\title{
Information Systems in Bangalore Traffic: A Case Study
}

\author{
Lakshmi Shankar Iyer*
}

Year 2012, month of March, Monday morning 8.30 a.m. Ramesh, a techie ${ }^{1}$ in his mid 30s with one of the popular software companies in Bangalore was on his way to office. He was waiting for the traffic signal to turn green in one of the busiest junctions of Bangalore city. As he was looking around, a traffic constable punching some numbers in his BlackBerry (BB) phone caught his attention. Standing in front of him was a bike rider without helmet (not wearing a helmet while riding a two wheeler being a punishable offence in the city of Bangalore). Ramesh recollected his thoughts when exactly two years ago Bharti Airtel ${ }^{2}$ distributed BB smart phones to most of the officers of the Bangalore traffic police. At that time Bangalore Traffic Police department claimed that BB would become an effective way of controlling traffic offences. Two years passed and Ramesh wondered whether the traffic offences in the city of Bangalore have really come down. Have the traffic police been able to track the repeat offenders? As he was pondering over these thoughts, the traffic signal turned green.

Assistant Professor, Department of Lean Operations and Systems, Christ University Institute of Management, Christ University, Bangalore. Email: lakshmi.iyer@christuniversity.in 


\section{Bangalore Traffic-A Decade Ago}

Ramesh, a native of Andhra Pradesh, a southern state of India has been living in Bangalore since the past four years. He migrated to Bangalore as it was one of the premier cities in India with well paid job opportunities due to the presence of Information Technology (IT) companies. According to old timers who stay in his locality, the distance of $15 \mathrm{kms}$ (9.32 miles) to his office was covered in 25 minutes a decade ago. In 2012, he failed to recollect even a single day wherein he reached his office in less than 75 minutes. Drives without traffic snarls to his office in his two-wheeler had become days of the past. This, he was told by his neighbours was due to increase in human as well as vehicle population.

Bangalore district population has ballooned by 46.68 percent over the past decade to around 9.59 million according to the 2011 Census survey. Commenting on the population growth in the district, K S James, Head, Department of the Population Research Centre for Social and Economic Change (ISEC) said "The growth seen in Bangalore district is totally unexpected. Migration has contributed significantly to the growth". (Bose, 2011)

The report Managing Asian Cities 2008 from Asian Development Bank shows that among Indian cities with 5 million or more residents, Bangalore is the second fastest growing city in terms of population. Bangalore, better known as Silicon City of India, has an annual population growth rate of $2.8 \%$, next only to Delhi $(3.5 \%)$ the capital city of India.

According to Jyotiprakash Mirji, the Commissioner of Traffic Police, Bangalore, "Unprecedented growth of Bangalore city as a result of proliferation of education institutions, IT/BT companies creating immense job opportunities and globalization coupled with pleasant weather has put tremendous pressure on transportation and traffic management. Inadequate infrastructure and inter mode public transport system has further aggravated the traffic scenario. The result is that more than 3.2 million vehicles ply in the city whereas it is difficult to handle even half of it". (Mirji, 2010) 


\section{Need for Traffic Solutions}

By 2010, Bangalore city roads had become increasingly congested due to the rapid growth in the city population. (Annexure 1). Traffic pressure in Bangalore was more pronounced due to the fact that there was very little scope for expansion of roads and there was a need to use existing roads for unhindered movement of vehicles. Obstruction of traffic movement by number of on-going works like fly-overs, underpasses, over-bridges made the management of traffic a herculean task. Heavy traffic congestion particularly in rush hours ended in late deliveries and caused delays for commuters in reaching their respective destinations. The corporate sector complained that due to late arrival of workers productive hours were lost. Emergency services were affected due to traffic congestion (Annexure 2). As city roads became increasingly congested, there was a dire need of change in transport policies to address the issue. On the other hand, the traffic department faced manpower crunch as it had not recruited since 2007. M N Sreehari, Traffic expert and Chairman of Traffic Engineers \& Safety Trainers (TEST) remarked "People say that the intelligence transport system as it is called elsewhere is very expensive. That is not the case. The system has come to existence in India because of human resources shortage." (Sreehari, 2011)

\section{B-TRAC 2010}

In 2010, the Bangalore city traffic police undertook several initiatives to streamline the traffic. One of the major initiatives was they envisaged the Bangalore Traffic Improvement Project - BTRAC 2010-a five year programme with estimated cost of about INR 35,00,00,000. This project was hailed as one of its kind in the country to address the issues of traffic congestion, safety and other traffic related issues utilizing the latest traffic management technology. It was considered that there was a smooth shift from policing the traffic to managing the traffic efficiently. B-TRAC also took initiatives to spread awareness and educate the citizen about the traffic rules. Another major feat achieved by Bangalore traffic police was that Bangalore became the only city in India with all traffic signals running on solar energy by the year 2010 . 
The action plan from B-TRAC was to create a reliable real-time traffic information system. Data collection happened through various components involved in the system. Thus the collected data were analysed and traffic intelligence was created. To enable public to take informed choices on the roads such information was disseminated through various modes. One of the prestigious projects from B-TRAC was the establishment of Traffic Management Centre (TMC).

\section{Traffic Management Centre}

The Traffic Management Centre at the Ashok Nagar Police Station, Bangalore has been the hub of transportation management system, where information about the transportation network were collected and combined with other operational and control data to manage the transportation network and to produce traveller information. TMC has been designed to house a traffic wireless system, traffic surveillance system, traffic signalling system, traffic help line, traffic planning operations and a few other services that were deployed under B-TRAC 2010. Surveillance cameras installed at various traffic junctions send live feed images to TMC on a real time basis. Enforcement cameras installed across the city transfer images of traffic violation TMC.

For quicker action on identification and reaction to any incident TMC linked various elements of Intelligent Transportation Systems. 19 traffic corridors were identified for peak hour traffic management. They were integrated into extended desktop formations. Roadblocks, diversions were intimated to the citizens of Bangalore through various FM radio channels. The integration was made possible by different software and hardware components built by technology firms like MindTree, CMS inforsystems, Bharat Electronics, Robert Bosch, IBM and Cisco. Google Earth was extensively used for identification of congested roads by commuters wherein the TMC would update the traffic density on a regular basis.

As a commuter drove across the city, he could never miss eyecatching boards with messages from traffic police. Traffic related information was disseminated through Variable messaging systems 
(VMS) across the city. 20 message boards mounted on large gantries were placed at convenient locations of the city for displaying traffic related information. This information was fed into terminals placed at TMC from where the message was relayed on to the boards using radio frequency waves. Travellers were able to make informed choices because of the information displayed about existing traffic scenario (Exhibit -3 Annexure 7).

\section{Surveillance and Enforcement Cameras}

Before the arrival of BTRAC-2010, manually monitoring the traffic offenders, catching them and slapping fine on them was a humongous task for the traffic police. But now, traffic offences like signal jumping, lane-crossing, riding without helmet could be tracked with visual evidence. With the presence of five enforcement high-resolution cameras across the city, pictures of over speeding vehicles and signal jumping vehicles were captured. The cameras which are on passive mode when the traffic lights turn red get activated when amber colour comes on. And when the green light is on, the cameras click photographs of the vehicle that has crossed the yellow line. TMC remotely monitored the various cameras put up at different junctions. These cameras had the capability to interpret the number plates using alpha numeric character recognition software. They were also connected to the central server at TMC. This means that when the police identified a target vehicle or a person (whenever a violation was noticed), they were able to zoom up to 200 metres from the spot, from the control room itself and capture the necessary information. This registration number would be matched with transport department database for generating fine notices to the registered owner of the concerned vehicle. With the help of 182 surveillance Pan-Tilt-Zoom (PTZ) cameras across the same number of junctions in the city of Bangalore live feeds were captured and passed on to TMC. This helped in regulation as well designing of traffic signals.

\section{Traffic Offences}

In 2012, the Union cabinet's decision to amend the Motor Vehicle Act in the year 2012 looked at a drastic fall in the number of traffic 
offences across the country. Once the new rules are in place, a steep rise in the earnings of state governments is expected. In Bangalore alone the earnings are expected to a five-fold increase in Karnataka's revenue. In the year 2011 nearly 4.8 million cases of traffic offences were booked and the state of Karnataka earned around INR 50,00,00,000 from them (Annexure 3). The same number of cases registered under the modified Motor Vehicle Act is expected to fetch the state close to INR 2,50,00,00,000 in the coming years. Additional commissioner of police (traffic and security) M A Saleem says, "As of now, INR 100 is the fine for almost all offences. But following the amendments, the base penalty will be as high as INR 500." (Chaturvedi, 2012)Though the purpose of the Bangalore Traffic Police is not to increase revenue, it was expected stringent penalties would deter people from flouting rules. A fined motorist could check the history of his past offences on the Bangalore traffic website. He has the option of paying the fine through Bangalore one centre ${ }^{2}$, online or at one of the designated police stations.

\section{Black Berry Driven Enforcement-A Boon?}

The Bangalore Traffic Police (BTP) equipped its officers with handheld Blackberry (BB) devices connected to Bluetooth-enabled printers to fine offenders and to enforce traffic rules and regulations. Traffic police were able to get access to the large central database of vehicles, drivers and offenders. Habitual traffic offenders, unpaid violation notices issued in past were tracked through BB devices. Bangalore Traffic Police were able to pull out data on more than two million cases in less than two minutes since all aspects of operational traffic policing was unified into a single system (Exhibit 1-Annexure 4).

However, the general public had its own share of doubts when BB was introduced by BTP to improve enforcement. Were the traffic police equipped to handle technology? Was it another publicity stunt by BTP? But time and again BTP proved the critics wrong. According to the BTP department, "The BB solution is a powerful tool, which not only enhances the visibility of a robust and a streamlined Traffic Enforcement System but also gives us an effective way to control traffic offences." (Bafna, 2010) 
Traffic police were trained and motivated to make use of BB. These devices being connected online to a central server at the state data centre (SDC). It ensured real time monitoring and statistical analysis for the senior officers' review. The traffic police would track repeat offender by feeding the licence number and name of the driver into the BB phone. When caught again, when the offender's licence number is punched in, the device would display all the past offences.

It was believed that this evidence based enforcement acted as a deterrent to commuters committing violations and also decreased the physical interaction between the police and the violator to the minimum. (Annexure - 5) For traffic offenders particularly who exceeded the speed limit, nine interceptor vehicles were deployed across the city, which were equipped with surveillance camera, alcometer and laser speed gun for recording the violation. (Exhibit 2 - Annexure 6)

There were 600 Bangalore Metropolitan Transport Corporation (BMTC), for public transportation in the Bangalore city were fitted with Global Positioning Systems (GPS) devices. This made identification of road congestion across Bangalore feasible. A real time Geographical Information System (GIS) reporting mechanism enabled to project the data thus collected into a map of the city. Incorporation of the basic traffic patterns for heavy traffic (red) medium congestion (orange) and free flowing traffic (green) was successfully done.

Integrated complaint monitoring systems helped in detecting defects like traffic signal lamp failure, input power supply failure. They were reported by the special controllers at the traffic junctions to the central server at the TMC. These huge networks required high levels of monitoring and surveillance. This mechanism would check the status of the components automatically and send SMS to the various field engineers. Keeping in mind the service orientation to keep downtime to the minimum the integrated complaint monitoring system_was accessible online. 


\section{Citizen Centric Steps}

In order to interact with public and to address their traffic related complaints and valuable suggestions, a platform was created by opening an account in Facebook, a social networking website. More than 31,000 people subscribed as on March 2012.

BTP sent free traffic alerts to its subscribers regarding traffic situation. Anyone could subscribe to the service by sending SMS JOIN $<$ SPACE $>$ BTP to 09219592195.

\section{Future Plans}

All these efforts led the traffic police department receive several accolades. BTP received Golden Peacock award for 'Innovative Product/Service' for adopting innovative use of technology through B-TRAC project. The Union Government of India recognised the B-TRAC project as one where technology was innovatively used in e-Governance. All the parking spaces in the city of Bangalore would be computerized so that it would be connected to the TMC to be centralised. The traffic police web site would receive the real time parking availability status from these parking places. This would enable the citizen's access to this data through VMS boards and SMS on a requirement basis.

The Traffic Training and Road Safety Institute, proposed to come up in Thanisandra, Bangalore, will cater to the requirements of training in traffic and road safety not only in Karnataka, but also the neighbouring states in the country. The facilities here would be utilized to train the police officers in traffic management and enforcement and also create awareness regarding road safety amongst all road users.

In spite of the use of technology in traffic management, there seemed to be other issues. Praveen Sood, the ex-additional commissioner of police remarked, "Traffic problem cannot be solved by technology alone. The infrastructure also has to be improved. However we can use technology to improve management and compliance". (PK, 2011) 
As the day was nearing its end, Ramesh while travelling home from his office recollected his thoughts. He was now convinced that besides making use of technology for better compliance the police have made use of technology in an efficient manner. He smiled, waved and nodded at the traffic cop at the junction and zoomed past towards his home.

\section{References}

Bafna, S. (2010, March 3). Retrieved May 21, 2012, from http:/ / telecomtalk.info/airtel-deploy-blackberry-services-for-bangaloretraffic-police/20747/

Bose, P. (2011, April 07). Population boom: At 46.68\%, Bangalore tops urban districts. Business Standard .

Chaturvedi, A. (2012, March 02). The route to road discipline. The Bangalore Mirror .

Mirji, J. (2010). Retrieved May 21, 2012, from http:/ / www.bangaloretrafficpolice.gov.in/index.php?option=com_conte $n t \&$ view $=$ article\&id $=52 \& b t p=52$

PK, J. (2011, March 17). Managing traffic through technology. The Economic Times, p. 4.

Sreehari, M. N. (2011, March 17). Managing traffic through technology. The Economic Times, p. 4. 
Lakshmi Shankar Iyer

ISSN 0975-3311

\section{Annexure}

\section{1 - Traffic Population in Bangalore City}

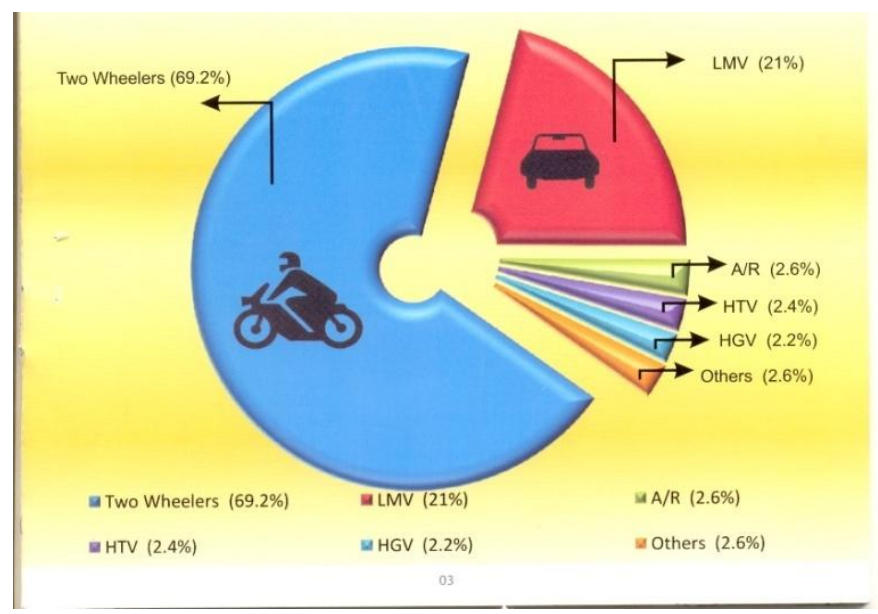

\section{2 - Registered Motor Vehicles in Bangalore City}

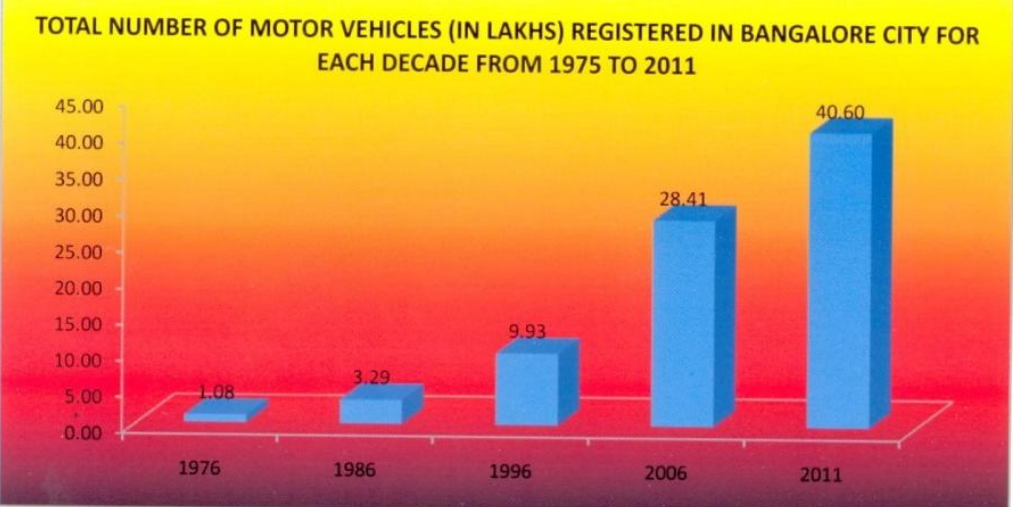




\section{3- Fine amount Collected}

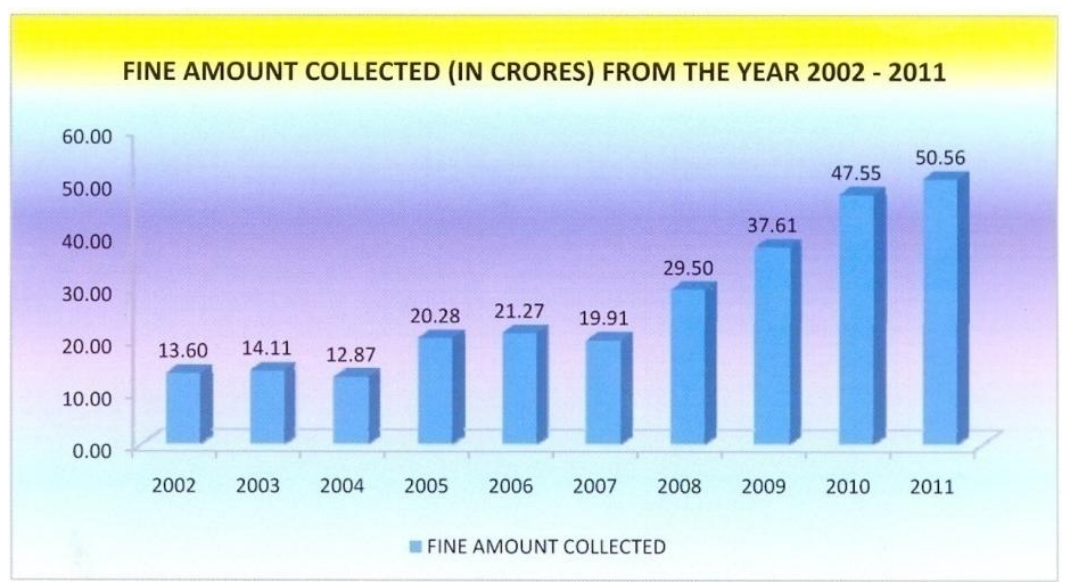

\section{4 - Blackberry Driven Enforcement-Exhibit 1}

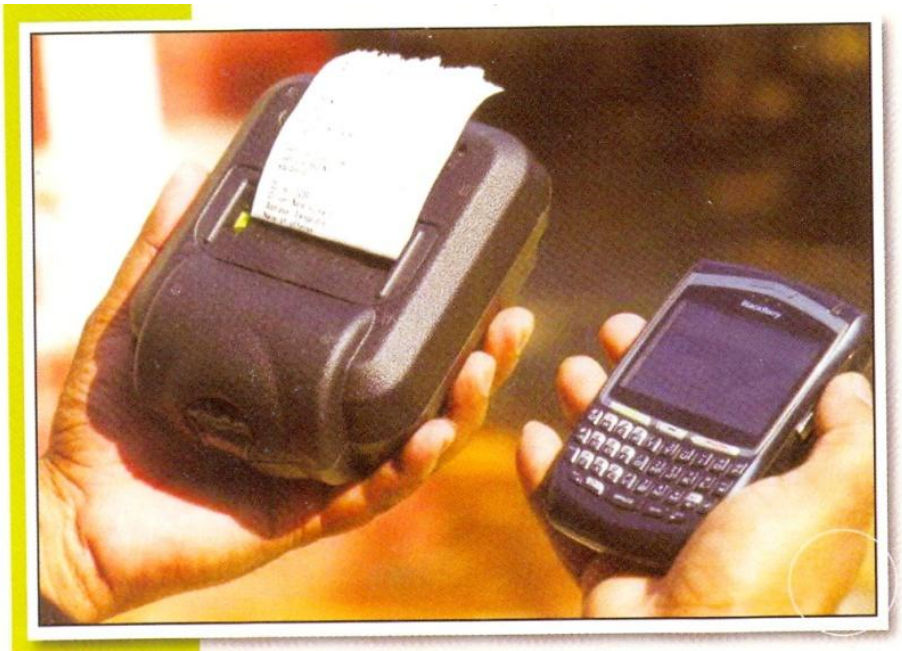




\section{5 - Traffic Offences}

\begin{tabular}{|c|c|c|c|c|c|c|}
\hline \multicolumn{7}{|c|}{$\begin{array}{c}\text { COMPARATIVE STATEMENT OF M.V.ACT CASES BOOKED IN DIFFERENT HEADS } \\
\text { FOR THE YEAR } 2008 \text { TO } 2012 \text { IN BANGALORE CITY }\end{array}$} \\
\hline $\begin{array}{l}\text { SI. } \\
\text { No. }\end{array}$ & Type of Offences & 2008 & 2009 & 2010 & 2011 & $\begin{array}{c}\text { 2012(upto } \\
31 / 03 / 2012 \text { ) }\end{array}$ \\
\hline 1 & Dangerous Driving & 86436 & 55567 & 50634 & 50086 & 16556 \\
\hline 2 & Over Speeding & 31001 & 63677 & 74787 & 71400 & 27664 \\
\hline 3 & Over Loading & 13617 & 14413 & 16157 & 24164 & 6805 \\
\hline 4 & Drunken Driving & 30593 & 38665 & 66930 & 61923 & 14929 \\
\hline 51 & Refuse to go for Hire & 14139 & 21820 & 34315 & 30924 & 10490 \\
\hline 6 & Demanding Excess Fare & 8639 & 11686 & 18976 & 17922 & 5401 \\
\hline 7 & A/R Display Card & 623 & 1626 & 1473 & 3075 & 1463 \\
\hline 8 & Defective Fare Meter & 63 & 39 & 121 & 26 & 8 \\
\hline 9 & Defective Silencer & 12814 & 12005 & 19222 & 12182 & 3655 \\
\hline 10 & Emitting Block Smoke & 10966 & 215 & 856 & 437 & 237 \\
\hline 11 & Shrill Horn & 26568 & 13286 & 32417 & 30174 & 4995 \\
\hline 12 & Without Permit & 2772 & 2314 & 2061 & 2308 & 488 \\
\hline 13 & Without D.L.. & 61102 & 40791 & 44091 & 45764 & 17816 \\
\hline 14 & Jumping Traffic Signal & 288705 & 558420 & 564731 & 493756 & 114612 \\
\hline 15 & Wrong Parking & 239639 & 377971 & 520962 & 696699 & 171656 \\
\hline 16 & Cutting Yellow Lane & 64548 & 117197 & 228147 & 219139 & 51404 \\
\hline 17 & Defective Registration No Plate & 49945 & 43188 & 52992 & 64707 & 18573 \\
\hline 18 & No Entry & 124399 & 282111 & 450056 & 432087 & 113582 \\
\hline 19 & HTV Prohibited & 50392 & 55441 & 76113 & 52387 & 16127 \\
\hline 20 & Without Uniform & 49897 & 62571 & 64302 & 66053 & 21655 \\
\hline 21 & Without I.C. & 24497 & 8834 & 6095 & 6291 & 2174 \\
\hline 22 & Without F.C. & 317 & 286 & 153 & 203 & 2 \\
\hline 23 & Defective Head Light & 20489 & 20348 & 17904 & 11911 & 5139 \\
\hline 24 & Defective Tail Light & 770 & 1019 & 782 & 439 & 323 \\
\hline 25 & Not Produce Documents & 47490 & 22460 & 23382 & 17951 & 6471 \\
\hline 26 & Over taking by left & 43199 & 25639 & 7908 & 3556 & 1028 \\
\hline 27 & Mobile Phone & 40282 & 64297 & 90332 & 132367 & 50941 \\
\hline 28 & Safety Belt & 636 & 900 & 1689 & 1760 & 53625 \\
\hline 29 & Without Helmet & 199862 & 230769 & 257072 & 320456 & 126054 \\
\hline 30 & Others & 240190 & 366084 & 475255 & 472437 & 98360 \\
\hline & TOTAL & 1784590 & 2513639 & 3199915 & 3342584 & 962233 \\
\hline
\end{tabular}




\section{6 - IT enabled Enforcement-Exhibit 2}

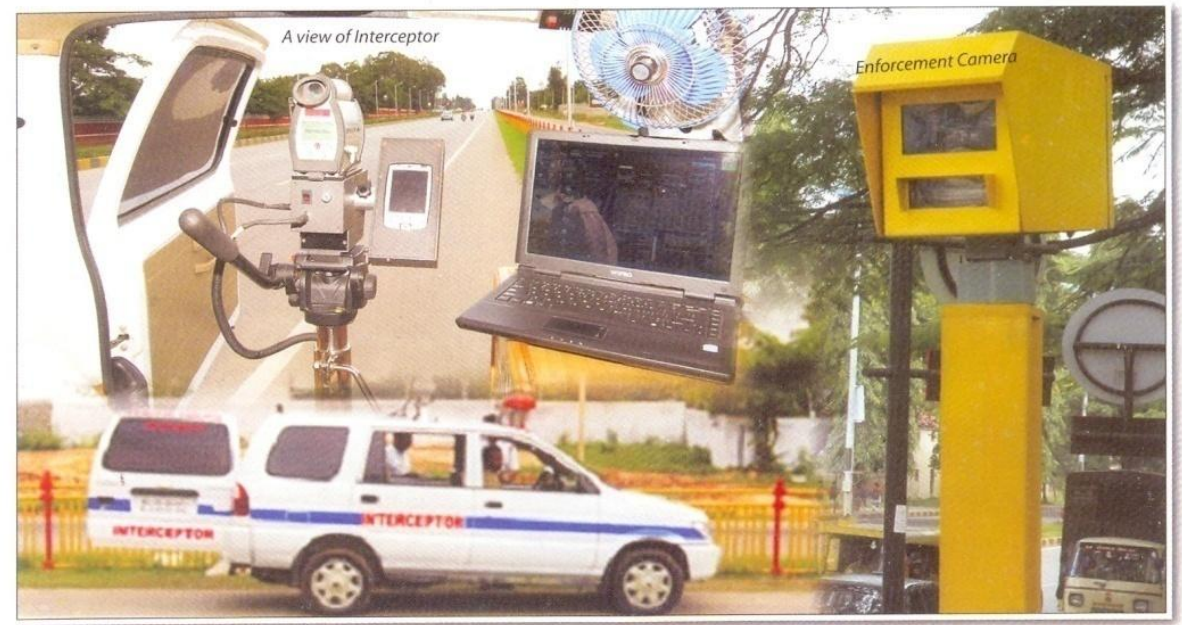

no

\section{7 - Variable Messaging Systems-Exhibit 3}

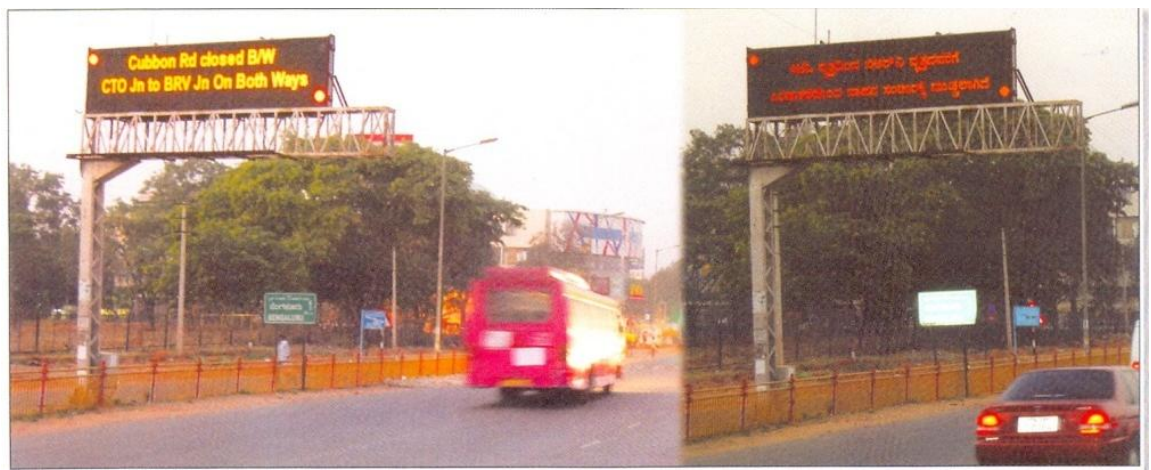

Source: B-TRAC, Government of Karnataka, Office of the Commissioner of Police, Bangalore City. 